\title{
A new tide model for the Antarctic ice shelves and seas
}

\author{
Laurie Padman, ${ }^{1}$ Helen A. Frigker, ${ }^{2}$ Righard Coleman, ${ }^{3,4}$ Susan Howard, ${ }^{1}$ Lana Erofeeva ${ }^{5}$ \\ ${ }^{1}$ Earth \& Space Research, 1910 Fairview Ave. E., Suite 102, Seattle, WA 98102-3620, U.S.A. \\ ${ }^{2}$ Institute of Geophysics and Planetary Physics, Scripps Institution of Oceanography, University of California San Diego, \\ La folla, CA 92093-0225, U.S.A. \\ ${ }^{3}$ Antarctic CRC and School of Geography and Environmental Studies, University of Tasmania, Box 252-80, Hobart, Tasmania 7001, Australia \\ ${ }^{4}$ CSIRO Marine Research, Box 1538, Hobart, Tasmania 7001, Australia \\ ${ }^{5}$ College of Oceanic \& Atmospheric Sciences, Oregon State University, Ocean Admin. Bldg. 104, Corvallis, OR 97331-5504, U.S.A.
}

\begin{abstract}
We describe a new tide model for the seas surrounding Antarctica, including the ocean cavities under the floating ice shelves. The model uses data assimilation to improve its fit to available data. Typical peak-to-peak tide ranges on ice shelves are 1-2 m but can exceed $3 \mathrm{~m}$ for the Filchner-Ronne and Larsen Ice Shelves in the Weddell Sea. Spring tidal ranges are about twice these values. Model performance is judged relative to the $\sim 5-10 \mathrm{~cm}$ accuracy that is needed to fully utilize ice-shelf height data that will be collected with the Geoscience Laser Altimeter System, scheduled to be launched on the Ice, Cloud and land Elevation Satellite in late 2002. The model does not yet achieve this level of accuracy except very near the few high-quality tidal records that have been assimilated into the model. Some improvement in predictive skill is expected from increased sophistication of model physics, but we also require better definition of ice-shelf grounding lines and more accurate water-column thickness data in shelf seas and under the ice shelves. Long-duration tide measurements (bottom pressure gauge or global positioning system) in critical datasparse areas, particularly near and on the Filchner-Ronne and Ross Ice Shelves and Pine Island Bay, are required to improve the performance of the data-assimilation model.
\end{abstract}

\section{INTRODUGTION}

Most of the mass loss from the Antarctic continent takes place from the floating ice shelves, via iceberg calving from their outer margins and basal melting beneath them (Jacobs and others, 1992). The surface height of an ice shelf varies in time with ocean tides, atmospheric pressure, ocean and ice density, snow loading, firn compaction, ablation or accretion of ice at the ocean/ice interface, and ice dynamics. These processes act over a wide variety of time-scales: from hours to decades and longer. The main cause of short-timescales: (less than seasonal) height variability will generally be ocean tides, with predicted peak-to-peak tide-induced displacements being $>3 \mathrm{~m}$ under some shelves. The largest tides occur in the Weddell Sea: a gravimeter record from near the grounding zone of the Rutford Ice Stream in the southern Ronne Ice Shelf shows peak-to-peak tidal changes of about $6 \mathrm{~m}$ (Doake, 1992). To accurately monitor long-term trends in ice-shelf surface height, the tide component must be removed from the height measurement, such that all iceshelf heights are referred to a "tide-free" datum.

The vertical displacement of an ice shelf can be measured to high accuracy using global positioning system (GPS) receivers placed on the ice (e.g. King and others, 2000), and interferometry from time-separated satellite synthetic aperture radar (SAR) images (e.g. Rignot and others, 2000). Satellite altimetry is the best approach to monitoring changes in ice-shelf height over time-scales of months to several years. A significant new dataset on iceshelf surface height will be obtained from the Geoscience Laser Altimeter System (GLAS), scheduled for launch in late 2002 on the Ice, Cloud and land Elevation Satellite
(ICESat). GLAS will provide measurements of ice-shelf surface height at $\sim 5 \mathrm{~cm}$ accuracy during its expected 3 year mission lifetime. On this time-scale, however, the height changes may be small compared with the high-frequency variability of tide height: perhaps tens of centimeters per year compared with the order $1 \mathrm{~m}$ standard deviation of the tides. Tides, with periods of $\sim 0.5$ and $\sim 1$ day, are undersampled by satellite repeat periods. ICESat, for example, will have a 183 day repeat interval for most of its planned 3 year mission, after $\sim 3$ months of an 8 day repeat cycle. Orbits can be designed to allow removal of tides from a long record of satellite altimeter data (Parke and others, 1987). At the time of writing, however, TOPEX/Poseidon (T/P) is the only satellite that is designed for this purpose (Smith, 1999; Smith and others, 2000), and it only provides coverage to latitude $\sim 66.2^{\circ} \mathrm{S}$. Therefore, the most effective method for predicting tides for removal from satellite data over Antarctic ice shelves is through numerical modeling.

In this paper we describe recent progress in modeling tides in the Southern Ocean. We treat tides as noise that must be removed from satellite data collected over ice shelves, so we focus here on prediction of tidal height rather than tidal currents. We note, however, that tides contribute directly to the dynamics and thermodynamics of ice shelves (see, e.g. MacAyeal, 1984; Makinson and Nicholls, 1999) and play a major role in setting the oceanic and sea-ice conditions north of the ice shelves (Robertson and others, 1998; Padman and Kottmeier, 2000). The distribution of tidal currents rather than height variability is the most significant factor affecting these processes; therefore accurate prediction of currents is also an important goal of our tidal studies, but is not discussed here. 


\section{TIDE-MODEL DESGRIPTION}

Several models of tides in the Southern Ocean already exist, including the global Finite-Element Simulation, version 95.2 (FES95.2: le Provost and others, 1997) and regional models, such as those for the Ross Sea (MacAyeal, 1984) and the Weddell Sea (Smithson and others, 1996; Robertson and others, 1998; Makinson and Nicholls, 1999). The Circum-Antarctic Tidal Simulation (CATS) (Padman and Kottmeier, 2000) covers the entire Southern Ocean south of $\sim 56^{\circ} \mathrm{S}$. While the predictive skill of recent versions of CATS is better than that of previous models, comparisons of predictions with a variety of datasets indicate that significant further improvement is still required.

Errors in present-day tide models arise from three sources: errors in forcing, primarily due to errors in openboundary specifications; simplifications in model physics; and errors in the water-column thickness grid. Simplifications of the physics are necessary to reduce computation time for a model run. Some simplifications (e.g. parameterizations of bottom friction and lateral mixing) apply to all tide models. When ice shelves are included, additional terms are required to account for some of the inelastic behavior of the ice. In our model, the shelves are treated as passive elements freely floating on a perturbed ocean "free" surface, and their only effects are to reduce the water depth and to provide an additional frictional surface (the ice/ocean interface) for dissipation of tidal energy (MacAyeal, 1984). Watercolumn thickness $(d)$ is the same as water depth for the open ocean, and is the vertical distance between the ice base and the seabed under the ice shelves (see fig. 1 in Smithson and others (1996) for a diagram of tide-model geometry). Errors in $d(x, y)$ are largest under the ice shelves. Indeed, even the precise location of the grounding line for sections of some ice shelves is still not known, although progress is now being made through satellite mapping (see, e.g., Gray and others 2002; Fricker and others, in press). The water-depth grid is slowly being improved (see Appendix) using additional data from cruises and re-analyses of existing ice-penetrating radar data, but more depth data are needed.

In the long term, improvements in tide modeling will result from an increase in model sophistication combined with a more accurate water-depth grid. In the shorter term, however, we adopt a data-assimilation (or "inverse") approach. An inverse model is a formalized hybrid of a purely empirical model (in which tidal constituents are determined from measurements) and a dynamical model in which predictions are based on solutions to the equations of fluid motion and known forcing (Robertson and others, 1998). Dynamical models, including CATS, are called "forward" models, because they are run by time-stepping the model equations and analyzing the time series after the model has reached equilibrium. One can think of assimilation as using data to objectively "nudge" a forward model such as CATS towards satisfactory agreement with the data, or using a physical model to provide a dynamically based scheme for interpolating and extrapolating tide values from sparse measurement sites onto a uniform grid. The details of the data-assimilation method that we follow are described in Egbert (1997). Here, we briefly describe the assimilated dataset and the relevant features of the final model, which we call the Circum-Antarctic Data Assimilation tides model, version 00.10 (CADA00.10).

In CADA00.10, tides for the entire ocean south of $58^{\circ} \mathrm{S}$ are modeled on a grid with node spacing of $1 / 4^{\circ} \times 1 / 12^{\circ}$ (about $10 \mathrm{~km}$ spacing near the Antarctic coast at $\sim 70^{\circ} \mathrm{S}$ ), using the depth grid described in the Appendix. The "prior" solution (i.e. the dynamically based "first estimate") is a linearized form of the CATS model, version 00.10 (CATS00.10). Four diurnal $\left(\mathrm{O}_{1}, \mathrm{~K}_{1}, \mathrm{P}_{1}, \mathrm{Q}_{\mathrm{U}}\right)$, four semi-diurnal $\left(\mathrm{M}_{2}, \mathrm{~S}_{2}, \mathrm{~K}_{2}, \mathrm{~N}_{2}\right)$ and two long-period (Mm, Mf) constituents are modeled.

Table 1. Tidal records used in model for assimilation or validation

No. Name Location Type $\begin{gathered}\text { Record Comments } \\ \text { length } \\ \text { days }\end{gathered}$

\begin{tabular}{|c|c|c|c|c|c|}
\hline 1 & Faraday & $65.25^{\circ} \mathrm{S}, 64.27^{\circ} \mathrm{W}$ & CTG & 365 & \\
\hline 2 & Forster & $70.77^{\circ} \mathrm{S}, 11.87^{\circ} \mathrm{W}$ & BPR & 307.25 & $\mathrm{NU}^{1}$ \\
\hline 3 & Rothera & $67.57^{\circ} \mathrm{S}, 68.12^{\circ} \mathrm{W}$ & CTG & 365 & \\
\hline 4 & Signy & $60.70^{\circ} \mathrm{S}, 45.60^{\circ} \mathrm{W}$ & BPR & 384.96 & \\
\hline 5 & PTC 4.2.1 & $77.12^{\circ} \mathrm{S}, 49.05^{\circ} \mathrm{W}$ & BPR & 4.2 & NU: short record \\
\hline 6 & PTC 4.2 .2 & $74.43^{\circ} \mathrm{S}, 39.40^{\circ} \mathrm{W}$ & BPR & 30 & $\mathrm{NU}^{2}$ \\
\hline 7 & PTC 4.2 .3 & $74.38^{\circ} \mathrm{S}, 37.65^{\circ} \mathrm{W}$ & BPR & 180 & \\
\hline 8 & PTC 4.2 .5 & $70.43^{\circ} \mathrm{S}, 8.30^{\circ} \mathrm{W}$ & BPR & 324 & \\
\hline 9 & PTC 4.2 .6 & $71.05^{\circ} \mathrm{S}, 11.75^{\circ} \mathrm{W}$ & BPR & 367 & \\
\hline 10 & PTC 4.2 .7 & $72.88^{\circ} \mathrm{S}, 19.62^{\circ} \mathrm{W}$ & BPR & 316 & \\
\hline 11 & PTC 4.2.19 & $60.05^{\circ} \mathrm{S}, 47.08^{\circ} \mathrm{W}$ & BPR & 408 & \\
\hline 12 & PTG 4.2.20 & $73.13^{\circ} \mathrm{S}, 72.53^{\circ} \mathrm{W}$ & BPR & 357 & Ronne Entrance \\
\hline 13 & PTG 4.2.24 & $61.47^{\circ} \mathrm{S}, 61.28^{\circ} \mathrm{W}$ & BPR & 320 & \\
\hline 14 & PTC 4.2.27 & $60.85^{\circ} \mathrm{S}, 54.72^{\circ} \mathrm{W}$ & BPR & 378 & \\
\hline 15 & PTC 4.2 .30 & $59.73^{\circ} \mathrm{S}, 55.50^{\circ} \mathrm{W}$ & BPR & 377 & \\
\hline 16 & PTC 4.2 .33 & $62.13^{\circ} \mathrm{S}, 60.68^{\circ} \mathrm{W}$ & BPR & 358 & \\
\hline 17 & PTG 4.2.34 & $70.13^{\circ} \mathrm{S}, 2.65^{\circ} \mathrm{W}$ & BPR & 653 & \\
\hline 18 & PTC 4.1.3 & $60.02^{\circ} \mathrm{S}, 132.12^{\circ} \mathrm{E}$ & BPR & 21 & NU: short record \\
\hline 19 & Mawson & $67.60^{\circ} \mathrm{S}, 62.87^{\circ} \mathrm{E}$ & BPR & 365 & \\
\hline 20 & Davis & $68.45^{\circ} \mathrm{S}, 77.97^{\circ} \mathrm{E}$ & BPR & 365 & \\
\hline 21 & Casey & $66.28^{\circ} \mathrm{S}, 110.53^{\circ} \mathrm{E}$ & BPR & 365 & \\
\hline 22 & RIS Base & $82.53^{\circ} \mathrm{S}, 166.00^{\circ} \mathrm{W}$ & Grav. & 44 & NU: validation \\
\hline 23 & RIS C13 & $79.25^{\circ} \mathrm{S}, 170.37^{\circ} \mathrm{E}$ & Grav. & 34 & NU: validation \\
\hline 24 & RIS C16 & $81.19^{\circ} \mathrm{S}, 170.50^{\circ} \mathrm{E}$ & Grav. & 45 & NU: validation \\
\hline 25 & RIS C36 & $79.75^{\circ} \mathrm{S}, 169.05^{\circ} \mathrm{W}$ & Grav. & 34 & NU: validation \\
\hline 26 & RIS F9 & $84.25^{\circ} \mathrm{S}, 171.33^{\circ} \mathrm{W}$ & Grav. & 58 & NU: validation \\
\hline 27 & RISJ9 & $82.37^{\circ} \mathrm{S}, 168.63^{\circ} \mathrm{W}$ & Grav. & 30 & NU: validation \\
\hline 28 & RIS LAS & $78.20^{\circ} \mathrm{S}, 162.27^{\circ} \mathrm{W}$ & Grav. & 32 & \\
\hline 29 & RIS McMurdo & $77.85^{\circ} \mathrm{S}, 166.66^{\circ} \mathrm{E}$ & BPR & 365 & \\
\hline 30 & RIS O19 & $79.53^{\circ} \mathrm{S}, 163.36^{\circ} \mathrm{E}$ & Grav. & 39 & NU: validation \\
\hline 31 & RIS RI & $80.19^{\circ} \mathrm{S}, 161.56^{\circ} \mathrm{W}$ & Grav. & 36 & NU: validation \\
\hline 32 & AIS Beaver Lake & $70.80^{\circ} \mathrm{S}, 68.18^{\circ} \mathrm{E}$ & BPR & 39 & \\
\hline 33 & AIS HWD-2000 & $69.71^{\circ} \mathrm{S}, 73.58^{\circ} \mathrm{E}$ & GPS & 31 & \\
\hline 34 & ROPEX C-1 & $59.87^{\circ} \mathrm{S}, 30.10^{\circ} \mathrm{W}$ & BPR & 445 & \\
\hline 35 & ROPEX C-2 & $73.69^{\circ} \mathrm{S}, 34.61^{\circ} \mathrm{W}$ & BPR & 393 & \\
\hline 36 & ROPEX M-2 & $76.58^{\circ} \mathrm{S}, 32.01^{\circ} \mathrm{W}$ & BPR & 377 & \\
\hline 37 & Rutford G.L. & $78.55^{\circ} \mathrm{S}, 82.97^{\circ} \mathrm{W}$ & Grav./tilt. & $4 / 43$ & \\
\hline
\end{tabular}

Notes: Faraday, Forster, Rothera and Signy data were obtained from the Proudman Oceanographic Laboratory (ACCLAIM dataset). PTC stations are from the Pelagic Tidal Constants publication (Smithson, 1992, and amendments). Mawson, Davis and Casey data are from the Southern Ocean Database at Australia's National Tidal Facility (NTF). Ross Ice Shelf (RIS) stations are as reported by Williams and Robinson (1980). The AIS Beaver Lake tide-gauge data were analyzed by the NTF, and the hot-water drill site (AIS HWD-2000) was collected by static GPS during January-February 2000 as part of the Australian Antarctic Science field program. ROPEX stations are unpublished data, provided by K.W. Nicholls and M.J. Smithson. Rutford grounding line (G.L.) data are based on 4 days of gravimeter data calibrated against tidal analysis of 43 days of tiltmeter data (Doake, 1992; Robinson and others, 1996). Data types are coastal tide gauges (CTG), bottom pressure recorders (BPR), gravimeters on the ice shelf (Grav.), or GPS.

NU, not used. Forster data disagree significantly with the forward model and data from Kapp Norwegia (PTC 4.2.6) and so are not used.

PTC 4.2.2, a 30 day record from the shelf break of the southern Weddell Sea, disagrees significantly with PTC 4.2.3, a much longer nearby record, and so is not used. 
These constituents are the same as those in the global tides model TPXO5.1 (personal communication from G. D. Egbert, 2000), which we use for model boundary conditions. The CATS00.10 model is driven by time-stepping TPXO5.1derived sea surface height along the northern open boundary at $58^{\circ} \mathrm{S}$, and by the astronomical tide-generating potential within the model domain. Sea ice is included neither in this forward model nor in the data-assimilation version (see following paragraph). In CATS00.10, the equations are solved for all constituents concurrently, and non-linearities can enter into the final tidal solutions through the quadratic bottom friction and momentum advection. One potentially important outcome of non-linearity in tide models is the establishment of mean flows, even though the basic forcing is entirely periodic (Makinson and Nicholls, 1999). Such flows are output by the forward model, but are lost in the assimilation model because it is based on linearized equations to make the inverse computations tractable.

Data assimilation was performed using the Oregon State University Tidal Inversion Software (OTIS: http:// www.oce.orst.edu/po/research/tide/index.html), which uses the "representer" approach to data assimilation (Egbert and others, 1994; Egbert and Bennett, 1996; Egbert, 1997). A total of 37 tide-gauge stations lie in our model domain (Table 1), including coastal sea-level gauges and bottom pressure recorders, and gravimeter measurements on the Ross and Ronne Ice Shelves. Twelve of these records were excluded, 4 because of uncertainties in their quality, and 8 gravimeter stations on the Ross Ice Shelf which are used to provide independent validation of model performance in this region. Representers were located at each of the remaining 25 sites, and an additional 270 representers were located

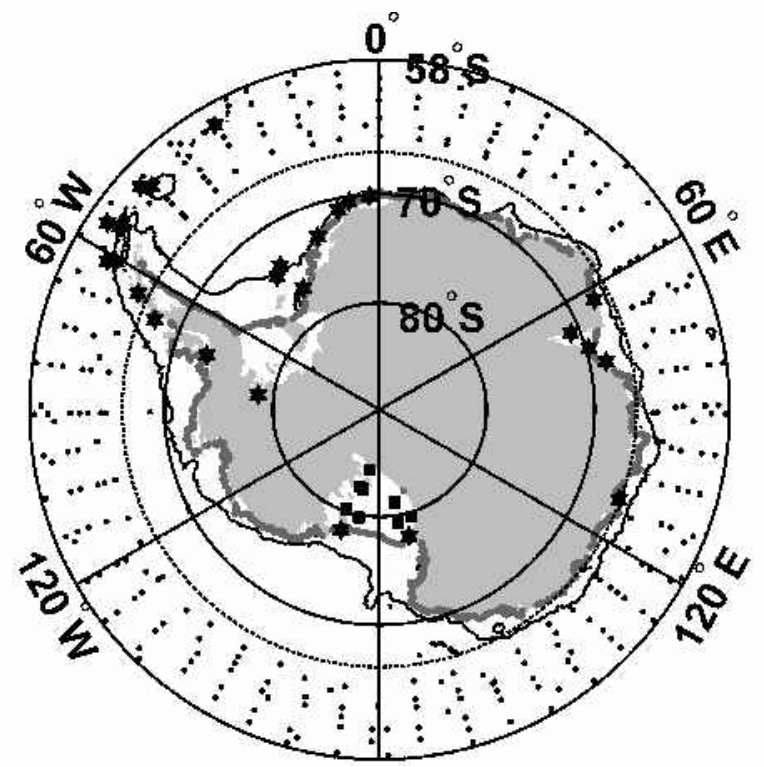

Fig. 1. Representer and data locations for the CADA00.10 model. The T/P satellite radar altimetry measurements are all north of $\sim 66.2^{\circ} \mathrm{S}$ (indicated by the dashed line). The 270 representer locations within the $T / P$ coverage area are shown as small dots. Asterisks indicate locations of non-T/P data records (Table 1) that are also used as representer sites in the assimilation. Solid squares on the Ross Ice Shelf show the locations of eight gravimeter records that are used in validating the tide models but are not used in the assimilation. Solid black contours indicate the 1000 and $3000 \mathrm{~m}$ isobaths, and the gray contour represents the ice fronts. in the $\mathrm{T} / \mathrm{P}$ data domain (north of $\sim 66.2^{\circ} \mathrm{S}$ ). Locations of all representers and the eight Ross Ice Shelf gravimeter records are shown in Figure 1. Note that the data south of the T/P data domain account for $<10 \%$ of the total number of representers. Their influence on the final model is greater than this, however, because the model-data misfit is scaled by a prior error covariance map, which in turn depends on the amplitude of the tides in the prior model solution. Since the largest tidal amplitudes are found in the southern and western Weddell Sea and Siple Coast section of the Ross Sea (see Fig. 2), data from these regions have a significant influence on the final inverse solution. Nevertheless, most of the inverse model improvement relative to the forward model is due to the tight constraints imposed by the $270 \mathrm{~T} / \mathrm{P}$-based representer sites north of $\sim 66.2^{\circ} \mathrm{S}$.

As a measure of the efficacy of data assimilation, in Table 2 we present the root-mean-square $(\mathrm{rms})$ error for the four major constituents, $\mathrm{M}_{2}, \mathrm{~S}_{2}, \mathrm{~K}_{1}$ and $\mathrm{O}_{1}$. These error estimates are calculated in the time domain, i.e. errors of both amplitude and phase are included in the calculations. We use two datasets, the 25 non-T/P sites used in the assimilation, and the eight gravimeter stations on the Ross Ice Shelf. Note that since the former dataset is used in the assimilation, improvements from the forward to the inverse solution are expected. In contrast, the gravimeter sites provide an independent check of the value of data assimilation as a dynamical means of data interpolation/extrapolation. With the exception of $\mathrm{M}_{2}$ on the Ross Ice Shelf, assimilation significantly improves the fit between the model and measurements. The fit of the inverse solution to the 25 assimilated sites, rms errors of 2-4 cm per constituent, is constrained by the choice of our expected error for each height measurement and our choice of a value for

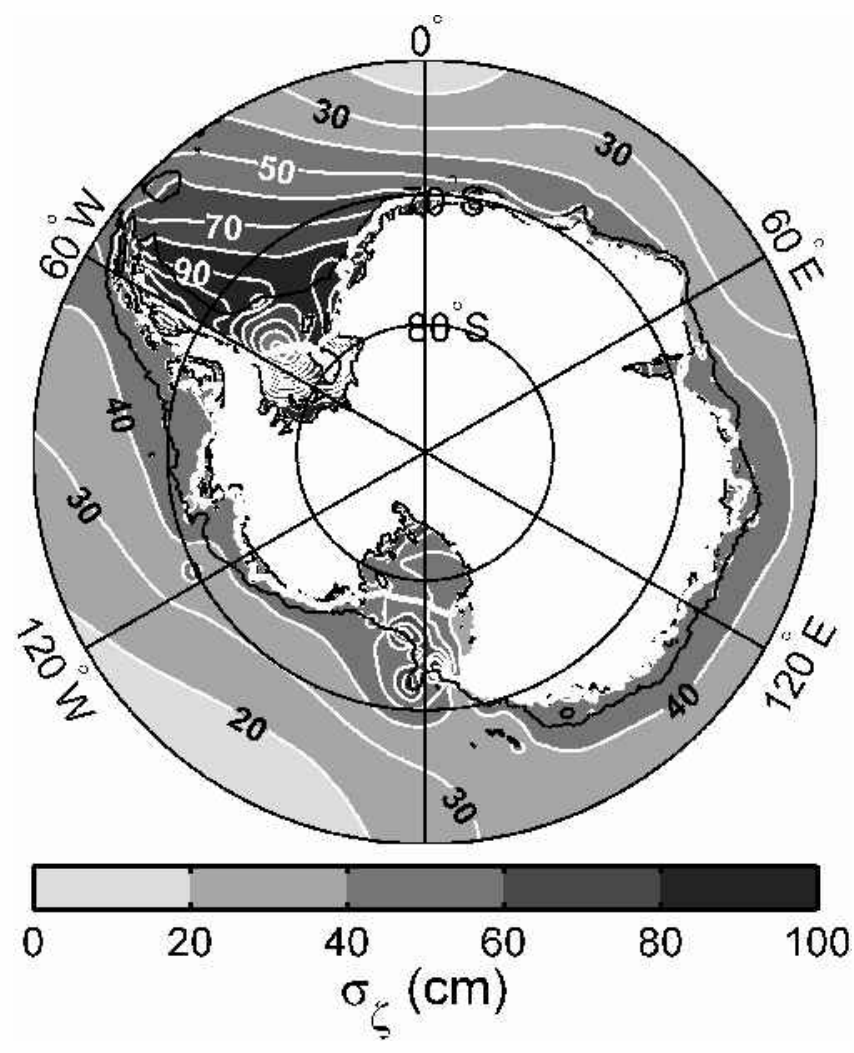

Fig. 2. Rms tide height $\left(\sigma_{\zeta}\right)$ for the entire circum-Antarctic seas to $60^{\circ} \mathrm{S}$. The thick white line is the SCAR 1993 ice-shelf edge. The black line is the $1000 \mathrm{~m}$ water-depth contour as a guide to the location of the continental slope. 
the OTIS parameter, $\sigma_{\varepsilon}$, which essentially measures the relative role of dynamics and assimilated data in constraining the final solution. Overconstraining the inverse model to height data results in height fields that are "bumpy", and unrealistic velocity fields and dynamic residual errors (the "error" forcing that is required to nudge the forward model solution to the inverse solution). Our choice of $\sigma_{\varepsilon}$, which is chosen separately for each species (semi-diurnal and diurnal), is presently based on a combination of subjective tolerance for height field variability, and informal comparisons of model predictions with other data types such as current-meter data and satellite interferometry.

The comparison of forward and inverse model skills in Table 2 indicates that further improvements are required under the Ross Ice Shelf. In a study of Ross Sea tides that will be reported elsewhere, we show that assimilating the eight gravimeter records from the ice shelf significantly improves model performance as judged by model comparisons with SAR interferometry data from the Siple Coast (personal communication from I. Joughin, 2001).

The full model grids for both CATS00.10 and CADA00.10 can be obtained on CD-ROM (in Matlab ${ }^{(i)}$ form) from the first author.

\section{MODEL RESULTS}

We characterize tidal-height variability by the standard deviation of the modeled tidal-height fields summed over all tidal constituents. This value, $\sigma_{\zeta}$, is given as a function of position $(x, y)$ by

$$
\sigma_{\zeta}(x, y)=\sqrt{\sum_{n=1}^{n=10} h_{n}^{2}(x, y)},
$$

where $h_{n}$ is the height amplitude of the $n$th tidal coefficient. The typical magnitude of the tidal range (low to high tide) is $\sim 2 \sigma_{\zeta}$. We also define a maximum height, $\zeta_{\max }$, given by

$$
\zeta_{\max }=\sum_{n=1}^{n=10} h_{n}
$$

Table 2. Comparison of the rms error (in $\mathrm{cm}$ ) between the modeled and measured tide heights for the four major tidal constituents, $M_{2} S_{2} O_{1}$ and $K_{1}$

$\begin{array}{cccc}M_{2} & S_{2} & O_{1} & K_{1} \\ \mathrm{~cm} & \mathrm{~cm} & \mathrm{~cm} & \mathrm{~cm}\end{array}$

\begin{tabular}{lllll}
\hline 25 assimilated sites & & & & \\
CATS00.10 & 3.9 & 4.7 & 5.1 & 3.4 \\
CADA001.0 & 2.4 & 2.4 & 3.9 & 2.0 \\
8 RIS gravimeter sites & & & & \\
CATS00.10 & 3.6 & 7.9 & 8.9 & 5.7 \\
CADA00.10 & 3.9 & 4.5 & 5.4 & 4.0
\end{tabular}

Notes: The comparison is performed for each site in the time domain, i.e. both amplitude and phase errors between modeled and measured constituent values are used. The two datasets for which mean rms statistics are presented are: the 25 non- $\mathrm{T} / \mathrm{P}$ data records that are included in the assimilation; and the 8 gravimeter records on the Ross Ice Shelf (RIS) that were not assimilated. Results are presented for the forward model, CATS00.10, and the inverse solution, CADA00.10. i.e. the height when all 10 explicitly modeled constituents are in phase. We do not show maps of this value, but the distribution of $\zeta_{\max }(x, y) / \sigma_{\zeta}(x, y)$ is narrow, with a mean value of $\sim 2$.4. The maximum peak-to-peak tidal range is $\sim 2 \zeta_{\max }$, or $\sim 4-5 \sigma_{\zeta}$. Slightly higher values are possible when the many minor tidal constituents are included in the summation in Equation (2) (see, e.g., le Provost and others, 1997).

In the following subsections we summarize the distribution of $\sigma_{\zeta}$ for three sectors of the Southern Ocean. Colorversions of the figures in this paper can be found at our web site, http://www.esr.org/antarctic.html.

\section{Weddell and Bellingshausen Seas}

Model values of $\sigma_{\zeta}$ exceed $150 \mathrm{~cm}$ in theWeddell Sea under sec-
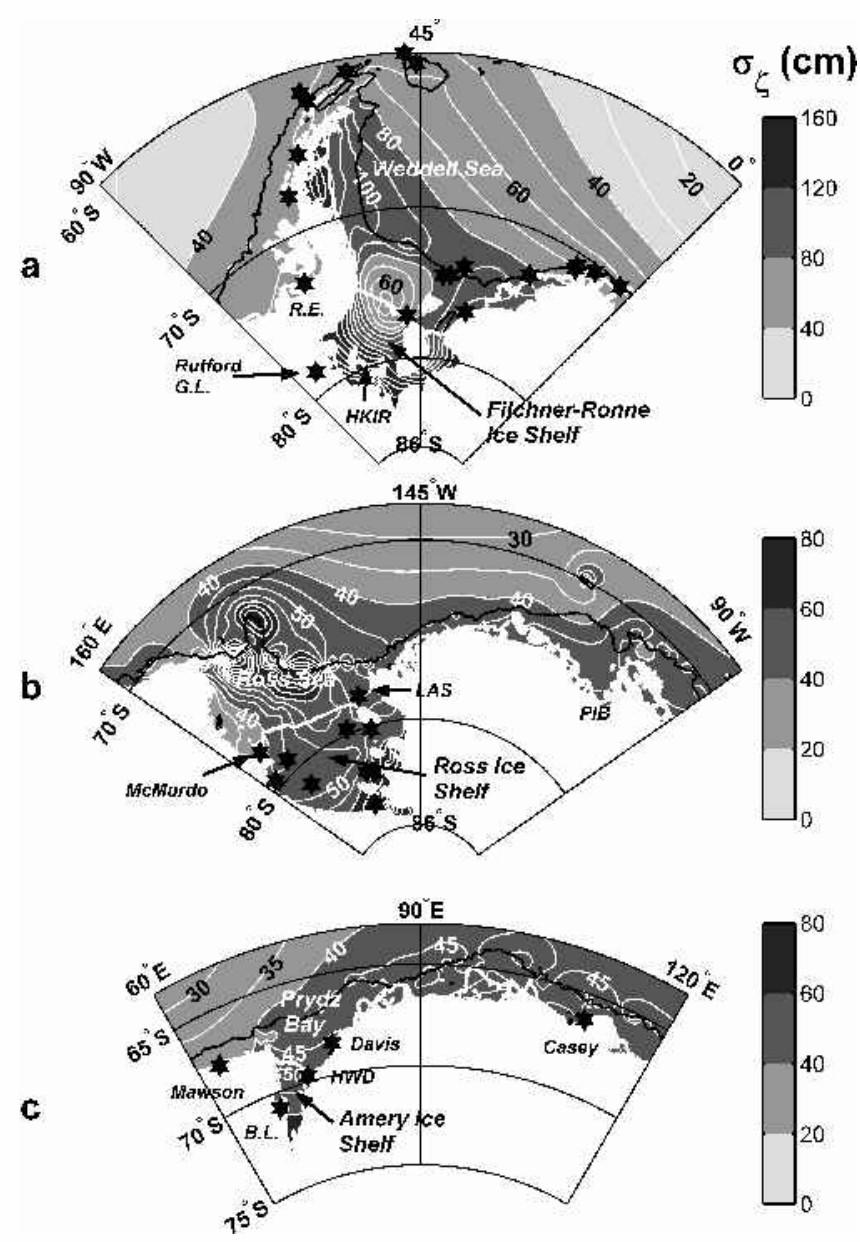

Fig. 3. Close-up of rms tide heights $\left(\sigma_{\zeta}\right)$ for three sectors. Asterisks indicate locations of non-satellite tide-height records listed in Table 1. (a) Weddell and Bellingshausen Seas. The highest values of $\sigma_{\zeta}$ in the southern Filchner-Ronne Ice Shelf are $>180 \mathrm{~cm}$ south of the Henry and Korff Ice Rises (HKIR). The locations of tidal measurements at Ronne Entrance (R.E.) and the Rutford grounding line (Rutford G.L.) are indicated. (b) Ross Sea to Pine Island Bay (PIB). The highest values of $\sigma_{\zeta}$ in the eastern Ross Ice Shelf are $>80 \mathrm{~cm}$ along the Siple Coast. The locations of tidal measurements at McMurdo Sound and the Little America Station (LAS) are indicated. (c) East Antarctic sector including the AIS. The highest values of $\sigma_{\zeta}$ in the southern AIS are $\sim 70 \mathrm{~cm}$. The locations of tidal measurements at Beaver Lake (B.L.) on the western side of the AIS, the GPS measurements at the hot-water-drilling site (HWD) and the Mawson, Davis and Casey stations are indicated. 
tions of the Ronne-Filchner and Larsen Ice Shelves (Fig. 3a). The spring tide peak-to-peak range exceeds $7 \mathrm{~m}$ in the channel south of the Henry and Korff Ice Rises in the southern Ronne Ice Shelf. This prediction is consistent with gravimeter records from near the grounding lines of the Doake Ice Rumples and Rutford Ice Stream, and site S902 (Smith, 1991; Doake, 1992; Robinson and others, 1996). The major semi-diurnal constituents, $\mathrm{M}_{2}$ and $\mathrm{S}_{2}$, dominate tide heights except near their amphidromic points close to the center of the Ronne Ice Shelf front.

Our modeled tide heights in this region are acceptable for most present purposes, even without assimilation: in differential SAR interferograms (DSIs) from the front of the Ronne and Filchner Ice Shelves (Rignot and others, 2000), the typical error between the differential height signal in the DSIs and the same signal synthesized from the nonassimilative CATS model was about $10 \mathrm{~cm}$. Tests in which we increased the benthic friction coefficient under the ice shelves, as a simple means to parameterize additional tidalenergy sinks, suggest that higher energy losses under the ice shelf further improve the fit of the CATS model to the icefront DSIs, although at the cost of poorer fits to open-ocean data. The best fit was found for an under-ice drag coefficient of $C_{\mathrm{D}}=0.015$, which is $\sim 5$ times greater than is typically used for benthic friction in ocean tide models. Smithson and others (1996) came to a similar conclusion: a higher value of $C_{\mathrm{D}}$ under ice shelves is required to reproduce some data, particularly near the grounding line, but also at the expense of degrading agreement at open-water sites. While some of the additional energy loss can be attributed to turbulence generation at the ice-shelf base, other energy sinks are needed to explain this large value of $C_{\mathrm{D}}$. Possibilities include inelastic flexure in the grounding zone, non-linear transfers to other frequencies, and generation of baroclinic tides. Identifying and parameterizing these additional energy sinks under ice shelves is a priority for future studies.

Smaller values of $\sigma_{\zeta}(\sim 50 \mathrm{~cm})$ occur in the Bellingshausen Sea. Three tidal stations, Faraday, Rothera and Ronne Entrance (Table 1), are available to test forward model performance in this region, and to constrain the inverse solution. In early versions of CATS, tides at Ronne Entrance $\left(73.13^{\circ} \mathrm{S}, 72.53^{\circ} \mathrm{W}\right)$ were very poorly represented when the model was run with the ETOPO-5 global bathymetry grid, in which the cavity under the George VI Ice Shelf was $20 \mathrm{~m}$ thick. The forward model performed much better, however, when the grid of $d(x, y)$ was adjusted to agree with values based on seismic sounding transects across the George VI Ice Shelf (Maslanyj, 1987). These transects showed that $d$ exceeds $600 \mathrm{~m}$ in a trough that runs under the entire length of this ice shelf, providing a conduit for tidal energy flux around the eastern side of Alexander Island that was essentially closed with the ETOPO-5 grid.

\section{Ross Sea to Pine Island Bay}

Under the Ross Ice Shelf, $\sigma_{\zeta}$ is $\sim 60 \mathrm{~cm}$, except for a small region of higher $\sigma_{\zeta}$ (up to $140 \mathrm{~cm}$ ) along the southern Siple Coast where Ice Streams A and C and Whillans Ice Stream enter the Ross embayment (Fig. 3b). Tides are predominantly diurnal except along the Siple Coast. However, the distribution of $d$ in this area is poorly known, and even the grounding-line location is uncertain: recent satellite data suggest that the Crary Ice Rise is actually connected to the
Siple Coast instead of being a separate feature as indicated in present coastline charts (Gray and others, 2002).

Tidal records for the Ross Ice Shelf are mainly gravimeter time series obtained in the 1970s (Williams and Robinson, 1980). With the exception of the Little America Station (LAS) point, these gravimeter data are not included in the data-assimilation runs discussed herein. The typical amplitudes for the two most energetic diurnal constituents, $\mathrm{K}_{1}$ and $\mathrm{O}_{1}$, are about $30-40 \mathrm{~cm}$. The rms error for the unassimilated gravimeter points (Table 2) is about 4 and $5 \mathrm{~cm}$, respectively, for $\mathrm{K}_{1}$ and $\mathrm{O}_{1}$, i.e. $10-20 \%$ of the true signal. Most of this error arises through phase errors: modeled diurnal amplitudes are within $2-3 \mathrm{~cm}$ of measured values. The weaker semi-diurnal constituents are very poorly represented in the model, even with assimilation of LAS and McMurdo Sound tide records. Both amplitude and phase errors are large. For one example, the $\mathrm{S}_{2}$ amplitude and phase at F9 (in the southeastern corner of the Ross Ice Shelf) is $11 \mathrm{~cm}$ and $142^{\circ}$ from data, but $28 \mathrm{~cm}$ and $187^{\circ}$ from CADA00.10. The rms error resulting from this misfit is $\sim 15 \mathrm{~cm}$, with maximum values of $\sim 22 \mathrm{~cm}$. That is, the error in $\mathrm{S}_{2}$ alone can exceed our nominal requirement of $\sim 10 \mathrm{~cm}$ for tidal prediction accuracy. The $\mathrm{S}_{2}$ constituent is difficult to predict because some of the $\mathrm{S}_{2}$ signal in data records is associated with ocean response to atmospheric radiational tides, and so is not modeled correctly by the shallow-water equations.

Three main factors contribute to the difficulty of modeling tides in the Ross Sea. First, T/P altimetry of the open-ocean surface is not available south of $\sim 66.2^{\circ} \mathrm{S}$, more than $1000 \mathrm{~km}$ north of the Ross Ice Shelf front. The T/P data provide the most rigorous constraint on the inverse model solution because of the good spatial coverage of the data in the northern part of our model domain. Second, $d(x, y)$ under the Ross Ice Shelf is poorly known, and may also have changed significantly since the surveys in the 1970s (see Gray and others, 2002). Third, no high-quality modern tidal records exist for the Ross Sea. The quality of the gravimeter records is unknown; hence, some of the difference between the model and the data may be due to data errors rather than model quality. (However, as we noted previously, assimilation of all the gravimeter sites does improve model comparisons with SAR interferometry estimates of tidal displacement.)

The value of $\sigma_{\zeta}$ in Pine Island Bay $\left(\sim 105^{\circ} \mathrm{W}\right)$ is $\sim 50-60$ $\mathrm{cm}$. Pine Island and Thwaites Glaciers are dynamic ice streams draining the West Antarctic marine ice sheet, and are believed to be presently out of dynamic equilibrium (Rignot, 1998; Wingham and others, 1998). Tide modeling is important for this region, both to assess the possible role of tides in the loss of shelf ice and to remove tide-height variability for satellite sensing of trends in ice-shelf thickness. There are, however, no tide data and very few bathymetry data in this region, so even our data-assimilation model is poorly constrained at this time.

\section{East Antarctica}

Along most of the coast of East Antarctica, $\sigma_{\zeta}$ is $\sim 40-55 \mathrm{~cm}$ (Fig. 2). However, under the Amery Ice Shelf (AIS) at the southern end of Prydz Bay, $\sigma_{\zeta}$ increases to $\sim 65 \mathrm{~cm}$ near the grounding line (Fig. 3c). Tides in this sector are mixed diurnalsemi-diurnal. Tidal currents under the ice shelf are small, typically $<5 \mathrm{~cm} \mathrm{~s}^{-1}$. With the exception of the AIS, much of the East Antarctic coastline lies close to the southern limit of T/P altimetry coverage, unlike the southern portions of the major 
embayments of the Weddell and Ross Seas. Tidal-height predictions in this sector are therefore relatively reliable in our model, because of the assimilation of $\mathrm{T} / \mathrm{P}$ data. As expected, due to the T/P constraints in CADA00.10, our model predictions for $\sigma_{\zeta}$ at Mawson, Davis and Casey stations are close to the measured values. For the AIS, errors in our forward model (CATS00.10), as judged by time-series comparisons between short GPS records and model predictions, increase further south. These data are not, however, of sufficient duration to be assimilated in CADA00.10, and so can only be used for model validation studies. When tides at Beaver Lake (a tidal lake to the west of the ice shelf) and the hotwater drilling site (HWD-2000) near the northwestern corner of the AIS are assimilated, the rms errors between model predictions and the GPS data further south are slightly reduced. Much of the error may, however, be due to the exclusion of non-tidal sources of height variability, and so would not be removed even if the tidal model were perfect.

\section{AN EXAMPLE OF TIDE-MODEL APPLICATION TO SATELLITE DATA}

Satellite orbit repeat periods $(\Delta T)$ are long compared with tidal time-scales, and so the satellite data undersample tidal variability. Tidal energy appears in the satellite record at an "aliasing frequency" that falls between 0 and $1 /(2 \Delta T)$. If the aliasing frequencies for the major constituents are separable during a mission life, then tidal information can be retrieved from the satellite records. This is true for the $\mathrm{T} / \mathrm{P}$ satellite, whose orbit was designed specifically for tidal retrieval (Parke and others, 1987). For other satellites, however, this is not the case. Smith (1999) and Smith and others (2000) compared aliasing periods for GEOSAT, the European Remotesensing Satellite (ERS) and T/P, and found that several problems arise. First, a constituent may be effectively "frozen"; that is, its alias period is long compared with the satellite's mission life, or even infinite. In this case, regardless of how large the constituent amplitude is, the recorded variability of that constituent is negligible during a mission. Second, two or more constituents may be aliased to nearly the same frequency, and so cannot be separated from each other. Third, constituents may be aliased to other frequencies at which non-tidal energy may be present. The most significant source of non-tidal energy is the annual response to cycles in oceanic or atmospheric conditions. The diurnal constituents $\mathrm{K}_{1}$ and $\mathrm{P}_{1}$ in the 35 day repeat phases of the ERS missions are both aliased to $\sim 1$ year periods and so cannot be separated from each other or from non-tidal, annual variability.

To demonstrate the aliasing problem, we show a 1 year time series of predicted tide heights for the point $71.5^{\circ} \mathrm{S}$, $70^{\circ} \mathrm{E}$ on the AIS, and the same time series sampled by the GLAS $\sim 8$ day repeat "Verification Phase" (Fig. 4). We show a full year of predictions, even though the Verification Phase is only planned to be 3 months long, to demonstrate the range of possible outcomes from a short mission. The apparent quasiannual cycle in the GLAS time series arises because two of the four largest semi-diurnal tides, $\mathrm{S}_{2}$ and $\mathrm{K}_{2}$, have aliasing periods of $\sim 1$ year. Another energetic constituent, the diurnal $\mathrm{K}_{1}$, has an aliasing period of about 2 years. During the first 100 days, GLAS sees significant short-period variability associated with the tide. From day 100 to day 200 the trend in height is downward, until it recovers in the last half of the year but with reduced short-period variability. If this entire

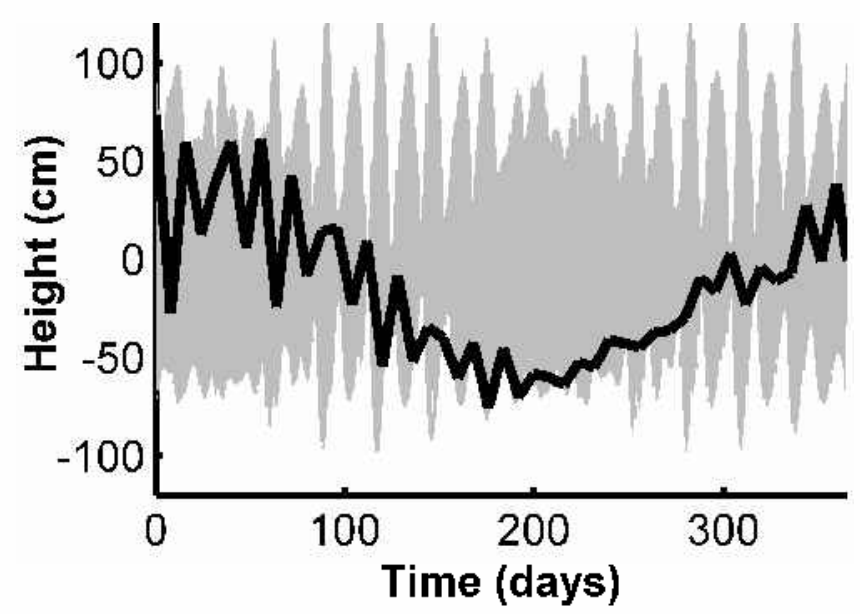

Fig. 4. Example of satellite aliasing problem. The thin gray line is the predicted hourly tide height for the point $71.5^{\circ} \mathrm{S}, 70^{\circ} \mathrm{E}$ on the AIS. The thick black line is the same tidal time series sampled at the GLAS sampling frequency during the 8 day repeat, Verification Phase of the ICESat mission. This phase will only last for 3 months, but we show 1 year of prediction to demonstrate the range of possible outcomes for an aliased time series that is shorter than the aliasing periods of major constituents.

signal was interpreted as being non-tidal, the apparent height change $(\Delta h)$ over 3 months of data collection could be as large as $60 \mathrm{~cm}$. If the GLAS time series was corrected with a tidal model, $\Delta h$ would be smaller but would still contain the aliased signal of the tide-model error. Thus, without an accurate tide model, tidal-height variability seen in the GLAS data may be misinterpreted as long-time-scale, nontidal, geophysical variability.

Another potential source of error over ice shelves that may be significant in satellite altimeter data is the inverse barometer effect (IBE). The isostatic response of the ocean surface to changing air pressure $\left(P_{\mathrm{atm}}\right)$ is a depression of $\sim 1 \mathrm{~cm}$ for each $1 \mathrm{mbar}$ increase in $P_{\text {atm }}$ (Gill, 1982, p. 337). A pressure anomaly of $\sim 30$ mbar associated with a typical polar low therefore leads to a $\sim 30 \mathrm{~cm}$ increase in sea level. There is some evidence from differential SAR interferometry that the IBE can be an important component of the residual height-change signal after tides have been removed (Rignot and others, 2000).

\section{CONGLUSIONS}

We have presented a new tide model for the Antarctic ice shelves and seas south of $58^{\circ} \mathrm{S}$. Data assimilation was used to constrain the model to better agreement with measurements of tide height. Typical peak-to-peak tidal ranges under most ice shelves fringing Antarctica are $\sim 1-2 \mathrm{~m}$. This can increase to $2-4 \mathrm{~m}$ at spring tides, and occasionally exceeds $6 \mathrm{~m}$, notably under the south of the Filchner-Ronne Ice Shelf (FRIS) in the southern Weddell Sea. Tides provide the major short-period signal that will be detected by satellite-based techniques such as SAR and laser altimetry. These instruments can detect height variability of $\sim 5 \mathrm{~cm}$ or smaller, yet we cannot provide tidal predictions at accuracies better than $10-20 \mathrm{~cm}$ for several critical segments of the Antarctic iceshelf area, notably the southern FRIS and the eastern side of the Ross Ice Shelf. Thus, the quality of tide models is pre- 
sently one of the factors preventing the full exploitation of these datasets.

Forward tide models based on the shallow-water equations can be improved by increasing the sophistication of the model physics and the accuracy of the water-column thickness grid. In an attempt to address the former requirement, we are currently investigating adding parameterizations for tidal energy loss to baroclinic tide generation, following Jayne and St. Laurent (2001), and changing the bottom drag coefficient to improve model fit to various datasets. We have found that increasing the parameterized tidal energy dissipation under ice shelves improves model skill along the Ronne and Filchner ice fronts when compared to displacements observed in DSIs (Rignot and others, 2000). However, the additional energy loss implied by this parameterization is much larger than one would expect from extra turbulence production at the ice-shelf base. This suggests that there is at least one more major physical mechanism for energy loss under ice shelves. Possible energy sinks not accounted for in our present forward model include inelastic flexure in the grounding zone, baroclinic tide generation, and/or transfer of tidal energy to other harmonics and terms through non-linear interactions, especially in the shallow water near the grounding zones.

The alternative approach to improving tide modeling, using an inverse technique such as data assimilation, requires that we increase the number of tidal records for assimilation. Satellite altimetry aside, most new data will consist of bottom pressure sensors moored in the ocean near the ice fronts, or static GPS on ice shelves controlled with nearby GPS on bedrock (e.g. King and others, 2000). In this case, care should be taken to obtain the ice-shelf records well away $(>10 \mathrm{~km})$ from the grounding line and shear margins, since the tide models presently do not include the glacial rheology needed to model tide-forced displacements within the flexural boundary layer. Models can predict phase and relative amplitude information closer to the grounding line but will overestimate absolute amplitude (Riedel and others, 1999). Ideally, the new measurements would be of long duration (e.g. 1 year), allowing good resolution of the major tidal constituents. However, shorter records are still useful: records of 30 days or longer can be analyzed for the major tidal constituents, and shorter records can be used for model validation. To our knowledge, the only current plan for significant tidal data collection is for the Amery Ice Shelf. Other areas, particularly the outlets of the major West Antarctic ice streams along the Siple Coast and Pine Island Bay, require new tide measurements.

One additional source of ice-shelf height variability that is not accounted for in our tide model is the IBE, which, as we discussed above, causes a change of $\sim 1 \mathrm{~cm}$ per $1 \mathrm{mbar}$ change in atmospheric pressure. Since typical pressure anomalies for polar low-pressure systems are $\sim 30$ mbar, an IBE response of $\sim 30 \mathrm{~cm}$ change in sea level is possible. This must be considered when attempting to "de-tide" satellitederived measurements of ice-shelf heights.

\section{ACKNOWLEDGEMENTS}

The ocean tidal modeling was supported by grants to Earth \& Space Research from the U.S. National Science Foundation Office of Polar Programs (OPP-9896041) and NASA (NAG57790). Funding for H.A.F. was provided by NASA grant NAS5-
99006 to GLAS Team Member J.-B. Minster. Work on the Amery Ice Shelf was supported by grants to R.C. from the Australian Research Council and the Antarctic Science Grant (ASG) scheme. Tidal sea-level analyses for Mawson, Davis and Casey stations and Beaver Lake were supplied by the NationalTidal Facility, The Flinders University of South Australia, copyright reserved. We thank the reviewers for their valuable comments on the manuscript.

\section{REFERENCES}

Brancolini, G. and 12 others. 1995. Descriptive text for the seismic stratigraphic atlas of the Ross Sea, Antarctica. In Cooper, A. K., P. F. Barker and G. Brancolini, eds. Geology and seismic stratigraphy of the Antarctic margin 1. Washington, DC, American Geophysical Union, 271-286. (Antarctic Research Series 68.)

Doake, C. S. M. 1992. Gravimetric tidal measurement on Filchner Ronne Ice Shelf. In Oerter, H., ed. Filchner-Ronne Ice Shelf Programme. Report No. 6 (1992). Bremerhaven, Alfred Wegener Institute for Polar and Marine Research, 34-39.

Egbert, G. D. 1997. Tidal data inversion: interpolation and inference. Progress in Oceanography, 40, 53-80.

Egbert, G. D. and A. F. Bennett. 1996. Data assimilation methods for ocean tides. In Malonette-Rizzoli, P., ed. Modern approaches to data assimilation in ocean modeling. Amsterdam, Elsevier, 147-179.

Egbert, G. D., A. F. Bennett and M. G. G. Foreman. 1994. TOPEX/POSEIDON tides estimated using a global inverse model. f. Geophys. Res., 99(C12), $24,821-24,852$

Fricker, H. A. and 8 others. In press. Redefinition of the grounding zone of Amery Ice Shelf, East Antarctica. 7. Geophys. Res.

Gill, A. E. 1982. Atmosphere-ocean dynamics. San Diego, Academic Press. (International Geophysics Series 30.)

Gray, L. and 6 others. 2002. RADARSAT interferometry for Antarctic grounding-zone mapping. Ann. Glaciol., 34 (see paper in this volume).

Greischar, L. and C. R. Bentley. 1980. Isostatic equilibrium grounding line between the West Antarctic ice sheet and the Ross Ice Shelf. Nature, 283(5748), 651-654.

Jacobs, S. S., H. H. Hellmer, C. S. M. Doake, A. Jenkins and R. M. Frolich. 1992. Melting of ice shelves and the mass balance of Antarctica. F. Glaciol., 38 $(130), 375-387$.

Jayne, S. R. and L. C. St. Laurent. 2001. Parameterizing tidal dissipation over rough topography. Geophys. Res. Lett., 28(5), 811-814.

Johnson, M. R. and A. M. Smith. 1997. Seabed topography under the southern and western Ronne Ice Shelf, derived from seismic surveys. Antarct. Sci., 9(2), 201-208.

King, M., L. Nguyen, R. Coleman and P. J. Morgan. 2000. Strategies for high precision processing of GPS measurements with application to the Amery Ice Shelf, East Antarctica. GPS Solutions, 4(1), 2-12.

le Provost, C., F. Lyard, J. M. Molines, M. L. Genco and F. Rabilloud. 1997. A hydrodynamic ocean tide model improved by assimilating a satellite altimeter derived dataset. 7. Geophys. Res., 103(C3), 5513-5529.

MacAyeal, D. R. 1984. Numerical simulations of the Ross Sea tides. F. Geophys. Res., 89(Cl), 607-615.

Makinson, K. and K.W. Nicholls. 1999. Modeling tidal currents beneath Filchner-Ronne Ice Shelf and on the adjacent continental shelf: their effect on mixing and transport. F. Geophys. Res., 104(C6), 13,449-13,465.

Maslanyj, M. P. 1987. Seismic bedrock depth measurements and the origin of GeorgeVI Sound, Antarctic Peninsula. Br. Antarct. Surv. Bull. 75, 51-65.

National Oceanic and Atmospheric Administration (NOAA). 1988. ETOPO5 bathymetry/topography data. Digital relief of the surface of the Earth. Boulder, CO, U.S. Department of Commerce. National Oceanic and Atmospheric Administration. National Geophysical Data Center. (Data Announcement 88-MGG-02.)

National Oceanic and Atmospheric Administration (NOAA). 1992. GEODAS CD-ROM worldwide marine geophysical data. Boulder, CO, U.S. Department of Commerce. National Oceanic and Atmospheric Administration. National Geophysical Data Center. (Data Announcement 9288-MGG-02)

Nicholls, K.W., L. Padman and A. Jenkins. 1998. First physical oceanography results from the ROPEX98 cruise to the southernWeddell Sea. In Oerter, H., comp. Filchner-Ronne Ice Shelf Programme (FRISP). Report No. 12 (1998). Bremerhaven, Alfred Wegener Institute for Polar and Marine Research, 51-58.

Padman, L. and Ch. Kottmeier. 2000. High-frequency ice motion and divergence in the Weddell Sea. F. Geophys. Res., 105(19), 3379-3400.

Parke, M. E., R. H. Stewart, D. L. Farless and D. E. Cartwright. 1987. On the choice of orbits for an altimetric satellite to study ocean circulation and tides. 7. Geophys. Res., 92 (C11), 11,693-11,707.

Riedel, B., U. Nixdorf, M. Heinert, A. Eckstaller and C. Mayer. 1999. The 
response of the Ekströmisen (Antarctica) grounding zone to tidal forcing. Ann. Glaciol., 29, 239-242

Rignot, E. J. 1998. Fast recession of a West Antarctic glacier. Science, 281(5376), 549-551.

Rignot, E., L. Padman, D. R. MacAyeal and M. Schmeltz. 2000. Observation of ocean tides below the Filchner and Ronne Ice Shelves, Antarctica, using synthetic aperture radar interferometry: comparison with tide model predictions. 7. Geophys. Res., 105(C8), 19,615-19,630.

Robertson, R., L. Padman and G. D. Egbert. 1998. Tides in the Weddell Sea. In Jacobs, S. S. and R. F. Weiss, eds. Ocean, ice and atmosphere: interactions at the Antartic continental margin. Washington, DC, American Geophysical Union, 341-369. (Antarctic Research Series 75.)

Robinson, A.V., C. S. M. Doake, K.W. Nicholls, K. Makinson and D. G. Vaughan. 1996. ESAMCA tidal correction report. Cambridge, British Antarctic Survey.

Scientific Committee on Antarctic Research (SCAR). 1993. Antarctic digital database. A topographic database for use with PC ARC/INFO, ArcView ${ }^{(m)}$ and ArcCAD ${ }^{\circledR}$. CD-ROM version 1.0, September 1993 edition. Cambridge, Scott Polar Research Institute, British Antarctic Survey and the World Conservation Monitoring Centre.

Smith, A. J. E. 1999. Application of satellite altimetry to global ocean tidal modeling. (Ph.D. thesis, Delft University of Technology. Delft Institute for Earth-Oriented Space Research.)

Smith, A. J. E., B. A. C. Ambrosius and K. F. Wakker. 2000. Ocean tides from T/P, ERS-1, and GEOSATaltimetry. 7. Geod., 74(5), 399-413.

Smith, A. M. 1991. The use of tiltmeters to study the dynamics of Antarctic ice-shelf grounding lines. 7. Glaciol., 37(125), 51-58.

Smith, W. H. F. and D.T. Sandwell. 1997. Global sea floor topography from satellite altimetry and ship depth soundings. Science, 277(5334), 1956-1962.

Smithson, M. J. 1992. Pelagic tidal constants 3. Del Mar, CA, International Union of Geodesy and Geophysics, International Association for the Physical Sciences of the Oceans. (IAPSO Publication Scientifique 35.)

Smithson, M. J., A.V. Robinson and R. A. Flather. 1996. Ocean tides under the Filchner-Ronne Ice Shelf, Antarctica. Ann. Glaciol., 23, 217-225.

Williams, M. J. M., R. C. Warner and W. F. Budd. 1998. The effects of ocean warming on melting and ocean circulation under the Amery Ice Shelf, East Antarctica. Ann. Glaciol., 27, 75-80.

Williams, R. T. and E. S. Robinson. 1980. The ocean tide in the southern Ross Sea. F. Geophys. Res., 85(C11), 6689-6696.

Wingham, D. J., A. L. Ridout, R. Scharroo, R. J. Arthern and C. K. Shum. 1998. Antarctic elevation change 1992 to 1996. Science, 282(5388), 456-458.

\section{APPENDIX \\ THE GATS/GADA DEPTH GRID}

Our $1 / 4^{\circ} \times 1 / 12^{\circ}$ model grid of $d(x, y)$ is based on ETOPO-5 (NOAA, 1988). Smith and Sandwell (1997) have developed a high-resolution depth grid for regions north of $72^{\circ} \mathrm{S}$, using gravity anomalies obtained from satellite altimeter heights to interpolate water depth between ship-track depth soundings. However, we have not yet developed a satisfactory scheme for merging this grid with our grid for regions south of $72^{\circ} \mathrm{S}$, and so have not yet implemented this improvement. Instead, we have updated several areas of specific interest using local depth grids. For the open Weddell Sea, we use a grid developed by Robertson and others (1998), which has been updated with depth data for the southwestern Weddell Sea acquired during the 1998 Ronne Polynya Experiment (ROPEX-98) (Nicholls and others, 1998). For the open Ross Sea, we use a grid generated from data acquired from the U.S. National Geophysical Data Center (NOAA, 1992). The resultant map of water depth for the open-water section of the Ross Sea is similar to that presented by Brancolini and others (1995). For the Amundsen Sea, including Pine Island Bay, we use ETOPO-5, but replace shallow shelf depths in ETOPO-5 with a more typical depth of $400 \mathrm{~m}$.

Water-column thickness for the ocean cavities under the major ice shelves was obtained from various sources. Gridded water-column thickness data for the FilchnerRonne Ice Shelf were obtained from Johnson and Smith (1997), and those for the Ross Ice Shelf were provided by D. Holland (personal communication, 1999) based on the measurements reported by Greischar and Bentley (1980). The Ross Ice Shelf cavity geometry was updated using the 1993 SCAR coastline (SCAR, 1993). Depths for the George VI Ice Shelf were obtained from Maslanyj (1987). For the AIS, $d(x, y)$ was obtained from Williams and others (1998), and the ice shelf was extended further south based on results of hydrostatic calculations (Fricker and others, in press). For all other ice shelves, $d(x, y)$ was taken from ETOPO-5. 